\title{
REVIEW
}

\section{Macrolide effects on the prevention of COPD exacerbations}

\author{
Mutsuo Yamaya*, Arata Azuma", Hajime Takizawa", Jun-ichi Kadota ${ }^{+}$, \\ Jun Tamaoki ${ }^{\S}$ and Shoji Kudoh ${ }^{f}$
}

ABSTRACT: The number of senile patients with chronic obstructive pulmonary disease (COPD) has recently increased due to an increase in life expectancy, the habit of smoking and the inhalation of toxic particles. COPD exacerbations are caused by airway bacterial and viral infections, as well as the inhalation of oxidative substrates. COPD exacerbations are associated with the worsening of symptoms and quality of life, as well as an increased mortality rate.

Several drugs, including long-acting anti-cholinergic agents, long-acting $\beta_{2}$-agonists and inhaled corticosteroids, have been developed to improve symptoms in COPD patients and to prevent COPD exacerbations. Treatment with macrolide antibiotics has been reported to prevent COPD exacerbations and improve patient quality of life and symptoms, especially in those patients who have frequent exacerbations. In addition to their antimicrobial effects, macrolides have a variety of physiological functions, such as anti-inflammatory and anti-viral effects, reduced sputum production, the inhibition of biofilm formation and the inhibition of bacterial virulence factor production. These unique activities may relate to the prevention of exacerbations in COPD patients who receive macrolides.

Herein, we review the inhibitory effects that macrolides have on COPD exacerbations and explore the possible mechanisms of these effects.

KEYWORDS: Anti-inflammatory effects, anti-viral effects, biofilm, chronic obstructive pulmonary disease exacerbation, mucus secretion, pro-inflammatory cytokines

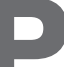
atients with chronic obstructive pulmonary disease (COPD) are treated with various types of drugs to improve their symptoms and quality of life (QoL), prevent exacerbations and reduce the mortality rate. These drugs include long-acting anti-cholinergic agents, long-acting $\beta_{2}$-agonists, inhaled corticosteroids and mucolytic agents [1-12]. Macrolides have a variety of physiological activities other than antimicrobial effects, including anti-inflammatory and anti-viral effects [13-26], reduced sputum production [27-30] and antimicrobial peptide production [31], in addition to inhibiting biofilm formation and reducing the bacterial production of virulence factors [32, 33]. These unique properties of macrolides have been suggested to contribute to the clinical benefits of macrolides in patients with diffuse panbronchiolitis (DPB) [34-36] and cystic fibrosis (CF) [37-40]. COPD exacerbations are caused by airway bacterial and viral infections [41-46], as well as the inhalation of oxidative substrates that induce airway inflammation [47, 48]. Based on the novel physiological activities of macrolides, we sought to investigate the clinical effects that macrolides have on the prevention of COPD exacerbations $[49,50]$. Other reports have also shown the effects that macrolides have on preventing COPD exacerbations and improving QoL in these patients [51-56]. Herein, we review the clinical effects of macrolides in COPD patients, including the prevention of exacerbations. Furthermore, we introduce the physiological activities of macrolides (such as their anti-inflammatory effects) to explore the mechanisms by which macrolides may contribute to the clinical effects observed in COPD patients.

\section{MACROLIDE EFFECTS ON COPD EXACERBATIONS}

\section{Prospective randomised study in Japan}

SUZUKI et al. [49] were the first to perform a prospective study on the clinical benefits that erythromycin has in preventing COPD exacerbations (table 1).

\section{AFFILIATIONS}

*Dept of Advanced Preventive Medicine for Infectious Disease, Tohoku University Graduate School of Medicine, Sendai,

"Division of Pulmonary Medicine, Infectious Diseases and Oncology, Dept of Internal Medicine, Nippon Medical School,

"Dept of Respiratory Medicine, Kyorin University Hospital,

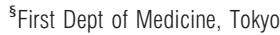
Women's Medical College,

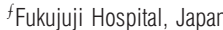

Tuberculosis Association, Tokyo, and +Internal Medicine II, Oita University Faculty of Medicine, Oita, Japan.

CORRESPONDENCE

M. Yamaya

Dept of Advanced Preventive Medicine for Infectious Disease Tohoku University Graduate School of Medicine

2-1 Seryo-machi

Aoba-ku

Sendai

980-8575

Japan

E-mail: myamaya@med.tohoku.ac.jp

Received:

Nov 272011

Accepted after revision:

Feb 082012

First published online:

March 092012 
TABLE 1 Clinical benefits of macrolides on chronic obstructive pulmonary disease patients

\begin{tabular}{|c|c|c|c|}
\hline First author [ref.] & Subjects $n$ & Drug(s) & Effects \\
\hline Suzukı [49] & 109 & Erythromycin & Reduction in the number of exacerbations and common colds \\
\hline YAMAYA [50] & 123 & Erythromycin or clarithromycin & $\begin{array}{c}\text { Reduction in the number of patients with exacerbations and the } \\
\text { number of patients experiencing hospitalisation }\end{array}$ \\
\hline Seemungal [51] & 109 & Erythromycin & $\begin{array}{c}\text { Reduction in the frequency of exacerbations } \\
\text { Shorter duration of exacerbation } \\
\text { Longer time to the first exacerbation }\end{array}$ \\
\hline $\mathrm{HE}$ [52] & 36 & Erythromycin & $\begin{array}{l}\text { Reduction in the exacerbation rate } \\
\text { Delay in the time to the first exacerbation }\end{array}$ \\
\hline BLASI [54] & 22 & Azithromycin & $\begin{array}{l}\text { Reduction in the number of exacerbations } \\
\text { Reduction in the number of hospitalisations }\end{array}$ \\
\hline ALBERT [53] & 1142 & Azithromycin & $\begin{array}{l}\text { Improvement in quality of life } \\
\text { Reduction in the frequency of exacerbations } \\
\text { Longer time to first exacerbation Improvement in quality of food }\end{array}$ \\
\hline
\end{tabular}

The authors performed a prospective, randomised, controlled (but not blinded) trial. A total of 109 patients with COPD were enrolled and randomly assigned to erythromycin therapy or no active treatment. The mean forced expiratory volume in $1 \mathrm{~s}$ (FEV1) values were $1.30 \mathrm{~L} \cdot \mathrm{s}^{-1}$ in the control group and $1.47 \mathrm{~L} \cdot \mathrm{s}^{-1}$ in the erythromycin group. COPD patients who exhibited bronchiectasis and DPB complications were excluded from the study. The patients in the erythromycin group received erythromycin 200-400 mg. day ${ }^{-1}$ and the patients in the control group received riboflavin in addition to sustained-release theophylline and inhaled anti-cholinergic agents. The observation period was 12 months. The authors did not examine the bacteria in the sputum in this study. The mean number of exacerbations and the mean number of common colds in the patients in the erythromycin group were lower than those in the control group. Furthermore, more patients were hospitalised due to exacerbations in the control group than in the erythromycin group. These findings suggest that erythromycin has beneficial clinical effects in moderate-to-severe COPD patients with frequent exacerbations due to upper respiratory tract infections. One patient in the erythromycin group had anorexia and diarrhoea and was excluded from the study, whereas the rest of the patients in the erythromycin group did not have any apparent adverse effects from erythromycin therapy during the study period. Based on these findings, the authors concluded that erythromycin therapy has beneficial effects on the prevention of COPD exacerbations. However, the authors also concluded that this intervention should be restricted to patients who are at high risk for COPD exacerbations because of the potential risk of the emergence of erythromycin-resistant pathogens.

\section{Multicentre retrospective study in Japan}

Because the prospective study by SUZUKI et al. [49] was performed in the hospitals within one prefecture in Japan, our group performed a multicentre study in Japan [50]. We analysed the records of 123 patients in seven Japanese university hospitals and one Japanese general hospital. Of this group, 45 patients received macrolide therapy (macrolide group) and 78 patients did not (control group). The proportion of macrolide-receiving patients with symptoms of sputum $(84 \%, \mathrm{p}<0.03)$ was larger than that in the control group $(68 \%)$. The macrolide-receiving patients were distributed among the Global Initiative for Chronic Obstructive Lung Disease (GOLD) classification stages as follows: GOLD stage I, 9\%; GOLD stage II, 67\%; GOLD stage III, 18\%; and GOLD stage IV 7\%. The severity of the GOLD stages in the macrolide group did not differ from the stage severity in the control group. The mean observation period was 42.9 months. The COPD patients participating in this study were treated with inhaled anti-cholinergic agents, long-acting $\beta_{2}$-agonists and sustained-release theophylline or inhaled steroids. The patients in the macrolide group received daily clarithromycin (200-800 mg.day ${ }^{-1}$ ) or erythromycin $\left(200-1,200 \mathrm{mg} \cdot \mathrm{day}^{-1}\right)$ for the observation period. A total of 41 patients were treated with clarithromycin or erythromycin alone, and another four patients were treated with clarithromycin and erythromycin at different times. The number of patients with an exacerbation frequency of $\geqslant 1.5$ times per year was lower in the macrolide group than in the control group. Likewise, the number of patients with a hospitalisation frequency of $\geqslant 0.75$ times per year was lower in the macrolide group than in the control group. The patients did not have any apparent adverse effects from erythromycin or clarithromycin treatment. This retrospective multicentre clinical study suggested that macrolide treatment may reduce the frequency of exacerbations and hospitalisation due to the exacerbations in Japanese patients with moderate-to-severe COPD who exhibit frequent exacerbations and hospitalisation and complained of sputum.

\section{Prospective, randomised, double-blind, placebo-controlled study}

Based on the report by SUZUKI et al. [49], SEEMUNGAL et al. [51] designed and performed a randomised, double-blind, placebocontrolled study to examine the effects of long-term erythromycin therapy on the prevention of COPD exacerbations. The authors randomised 109 outpatients and observed the number of exacerbations for 12 months. Patients were included in the study if they had moderate-to-severe COPD with FEV1 between $30 \%$ and $70 \%$ predicted. The mean FEV1 and FEV1 \% predicted values 
of the enrolled patients were $1.32 \mathrm{~L} \cdot \mathrm{s}^{-1}$ and $50 \%$, respectively. Of these, 38 patients had three or more exacerbations in the year prior to recruitment. The patients received inhaled steroids (78\%), long-acting $\beta_{2}$-agonists (63\%), long-acting anti-cholinergic agents $(33 \%)$ or theophylline $(11 \%)$. Furthermore, 53 patients in the erythromycin group received erythromycin (250 $\mathrm{mg}$ twice daily). There was a total of 206 moderate to severe exacerbations in 109 of the patients who were enrolled, with 125 exacerbations occurring in the 56 patients in the placebo group. The frequency of moderate to severe exacerbations in the erythromycin group was lower than that in the placebo group. The duration of exacerbations in the erythromycin group was shorter than that in the placebo group, and the time to first exacerbation was longer for the erythromycin group than for the placebo group. There was no significant difference in adverse effects between the erythromycin and placebo groups. The frequency of adverse effects was low in both groups. In some cases, more than one adverse effect occurred in the same patient; e.g. an upper gastrointestinal symptom occurred in a patient who also had tinnitus.

There was no difference in the microorganism detection rate in the spontaneously produced sputum of the two study groups at any of the follow-up time-points over the 1-yr study period. Of the samples taken during stable conditions, $27 \%$ tested positive for Haemophilus influenzae, as did $40 \%$ of the samples taken during an exacerbation. The distribution for Streptococcus pneumoniae was $7 \%$ during stable conditions and 10\% during exacerbation. Furthermore, pathogens were detected in 17 out of the 43 sputum samples at the 12-month follow-up visit and included $H$. influenzae (placebo group $n=3$, macrolide group $\mathrm{n}=1$ ), $S$. pneumoniae (placebo group $\mathrm{n}=2$, macrolide group $\mathrm{n}=1$ ) and Moraxella catarrhalis (placebo group $\mathrm{n}=2$ ). Sensitivity tests showed that all four of the $H$. influenzae samples were resistant to erythromycin and one $S$. pneumoniae sample from the macrolide group was also resistant to erythromycin. Based on the findings of the sensitivity test, the authors suggested that there were no differences between the macrolide and placebo groups in terms of the bacterial flora in the sputum [51]. The authors concluded that macrolide therapy may be useful in decreasing the excessive disease burden in patients with COPD. Macrolide therapy may have clinical benefits in moderate-tosevere COPD patients with frequent exacerbations.

HE et al. [52] performed a randomised, placebo-controlled, double-blind erythromycin trial for a 6-month period. In this study, 36 COPD patients were randomised to treatment with oral erythromycin $(n=18,125 \mathrm{mg}$ three times per day) or placebo $(n=18)$ daily. A total of 31 patients completed the study (16 patients in the erythromycin group and 15 patients in the placebo group). The mean FEV1 value was $1.1 \mathrm{~L} \cdot \mathrm{s}^{-1}$ in both groups, and the FEV1 \% predicted value was $42 \%$ in the placebo group and $44 \%$ in the erythromycin group. These values suggest that primarily severe COPD patients were enrolled in the study. There were a total of 31 moderate-severe exacerbations over the 6-month treatment period, of which 20 occurred in the placebo group and 11 in the erythromycin group. Erythromycin therapy reduced the mean exacerbation rate and delayed the time to the first exacerbation. The neutrophil counts and neutrophil elastase levels in the sputum were decreased in the patients in the erythromycin group. Two patients discontinued their participation in the study. One patient had abdominal pain after erythromycin treatment, and another experienced left heart failure. A bacterial examination test showed that there was no difference in the detection rates for the three main microorganisms (S. pneumoniae, H. influenzae and $M$. catarrhalis) between the two groups at baseline or after 6 months of treatment. The three main pathogens that were detected at the 6-month time-point were S. pneumoniae (placebo group $\mathrm{n}=3$, erythromycin group $\mathrm{n}=2$ ), $H$. influenzae (placebo group $n=2$, erythromycin group $n=2$ ) and $M$. catarrhalis (placebo group $n=2$, erythromycin group $n=1$ ). The authors concluded that erythromycin treatment in COPD patients can reduce airway inflammation and decrease exacerbations, and may therefore be useful in the management of COPD. Erythromycin therapy may reduce the frequency of exacerbations and airway inflammation in severe COPD patients who experience frequent exacerbations.

BANERJEE et al. [13] performed a controlled study in 67 patients with COPD. The patients were randomised to 3 months of clarithromycin (500 mg daily) or placebo and were observed for 3 months. Overall, 26 patients receiving clarithromycin and 34 receiving placebo completed the trial. The mean FEV1 value was $44 \%$ pred in the placebo group and $43 \%$ pred in the clarithromycin group. These values suggest that primarily severe GOLD stage COPD patients were enrolled in the study. One patient from the clarithromycin group had gastrointestinal symptoms and withdrew from the study. The pathogen growth rate in the sputum of the clarithromycin group was similar before treatment (55\%) and after 3 months of treatment $(58 \%)$. However, the frequency of exacerbations in the clarithromycin group $(n=5)$ did not differ from that of the control group $(n=2)$. The exacerbation frequency was smaller in this study than in others [49-53]. Macrolide therapy may not be necessary in patients who do not have frequent exacerbations.

\section{Randomised trial investigating the effects of azithromycin}

To examine the effects that macrolide therapy has on COPD exacerbations, ALBERT et al. [53] performed a prospective, parallel-group, placebo-controlled study, for which 1,577 subjects were screened. Moderate-to-very severe GOLD stage COPD patients were enrolled in this study. None of the COPD patients were in mild GOLD stage. The mean FEV1 value was $1.1 \mathrm{~L} \cdot \mathrm{s}^{-1}$ in both the placebo and azithromycin groups, and the mean FEV1 \% predicted value was $40 \%$ in the placebo group and $39 \%$ in the azithromycin group. The patients were either using continuous supplemental oxygen or had received systemic glucocorticoids within the previous year [53]. The patients had visited an emergency room or had been hospitalised for an acute COPD exacerbation, but had not experienced an acute COPD exacerbation for at least 4 weeks before enrolment [53]. A total of 1,142 (72\%) patients were randomly assigned to receive $250 \mathrm{mg}$ azithromycin $(n=570)$ or placebo $(n=572)$ daily for $1 \mathrm{yr}$ (in addition to their usual care). In addition to azithromycin or placebo, the patients received inhaled steroids (76\%), longacting $\beta_{2}$-agonists $(73 \%)$, long-acting anti-cholinergic agents $(62 \%)$ or no medication $(9 \%)$ as their usual care. The time to the first exacerbation was longer in the azithromycin group than the placebo group, and the COPD exacerbation frequency in the azithromycin group was lower than that in the placebo group. The rate of COPD exacerbations per patient per year was 1.48 in the azithromycin group and 1.83 in the placebo group, and the exacerbation rates in this study were higher than those in the 
other previously reported $[49,50]$. The total St George's Respiratory Questionnaire scores decreased in the azithromycin group, showing an improvement in patient QoL.

No significant differences were observed in the frequency of serious adverse events or adverse events leading to the discontinuation of the study drug. However, hearing decrements were more common in the azithromycin group ( $n=142,25 \%)$ than in the placebo group $(n=110,20 \% ; p=0.04)$. Although all of these COPD patients should have had their study drug discontinued, the drug was discontinued in only $61(76 \%)$ patients in the azithromycin group and $37(82 \%)$ in the placebo group, owing to protocol errors.

At the time of enrolment, the rate of selected respiratory pathogen colonisation in the nasopharyngeal swabs from the azithromycin group (14\%) did not differ from that in the placebo group (15\%). However, more patients in the placebo group (31\%) than the azithromycin group (12\%) became colonised during the course of the study. Susceptibility testing revealed that the prevalence of respiratory pathogen resistance to macrolides in the azithromycin group (52\%) did not differ from that in the placebo group $(57 \%, \mathrm{p}=0.64)$ at the time of enrolment. In contrast, the test investigating the pathogens from the COPD patients who were not colonised at the time of enrolment but became colonised during the course of the study revealed that the incidence of resistance to macrolides was higher $(81 \%)$ in the azithromycin group than the placebo group $(41 \%, \mathrm{p}<0.001)$. Thus, COPD patients receiving azithromycin were less likely to become colonised with respiratory pathogens but were more likely to become colonised with macrolideresistant organisms [53].

Based on these findings, the authors concluded that azithromycin treatment decreased COPD exacerbations and improved QoL, but caused hearing decrements in a small percentage of subjects [53]. This study suggested that treatment with azithromycin has clinical benefits in COPD patients with severe conditions.

\section{Studies using other designs}

The efficacy of treatment with $500 \mathrm{mg}$ of azithromycin 3 days per week was evaluated for 6 months in a multicentre, randomised, uncontrolled pilot study of tracheostomised COPD patients [54]. $10(46 \%)$ patients received long-term oxygen therapy. An average number of exacerbations in the previous year was 3.1 (standard care group) and 3.0 (azithromycin group). These values suggest the severe conditions of the patients who were enrolled. A total of 22 patients were randomised, and the cumulative number of exacerbations and hospitalisations was lower for the patients in the azithromycin group than the patients in the standard care group. Azithromycin also improved the patients' QoL in comparison to standard care. No serious adverse events were reported in the azithromycin group. Four patients experienced mild adverse events (diarrhoea, $n=3$; stomach ache, $n=3$ ). A total of six of the 11 patients in the azithromycin group and five of the 11 patients in the standard care group were colonised with $P$. aeruginosa at baseline. Two of the azithromycin-treated patients who were initially colonised with $P$. aeruginosa exhibited reduced colony counts after 3 months of treatment, and the microorganism was eradicated in one patient. In contrast, $P$. aeruginosa became resistant to ceftazidime and an erythromycin-resistant $S$. pneumoniae strain was identified in one patient after 6 months of treatment with azithromycin. The authors concluded that long-term azithromycin treatment seems to be safe and effective in severe COPD outpatients with tracheostomy in reducing exacerbations and hospitalisations, as well as in improving QoL.

GOMEZ et al. [56] examined the effects of azithromycin in 54 COPD patients in a prospective, randomised study. The patients were treated with $500 \mathrm{mg}$ azithromycin daily for 3 days every 21 days during the winter months [56] and were compared to the control group of patients who did not receive treatment. The authors reported that the frequency of acute infectious episodes and hospitalisations was lower in the azithromycin group than in the control group.

\section{Macrolide effects on bronchiectasis}

The presence of bronchiectasis is suggested to be important for the pathogenesis of COPD exacerbations [57]. A recent report demonstrated that $>50 \%$ of COPD patients were shown to have bronchiectasis with severe airflow obstruction and at least one hospitalisation for COPD exacerbation in the previous year [58]. Macrolide therapy improves sputum purulence, airway hypersensitivity [59], lung function and sputum volume [27, 60-63], and symptom scores in patients with bronchiectasis, in addition to reducing the frequency of exacerbations $[63,64]$.

Treatment with clarithromycin or erythromycin did not change the total amount of bacteria, the bacterial flora or the pathogenic densities in the sputum of patients with bronchiectasis [27, 61]. Likewise, a recent study by SERISIER and MARTIN. [65] demonstrated that 12 months of erythromycin therapy reduced the frequency of exacerbations in patients with bronchiectasis, and that neither new respiratory pathogens nor erythromycin resistant organisms were detected in the sputum during the study.

These findings suggest the possibility that macrolides may have clinical benefits in COPD patients with bronchiectasis, although small numbers of patients were studied.

\section{ADVERSE EFFECTS OF LONG-TERM MACROLIDE THERAPY IN COPD}

Long-term treatment with macrolides has been suggested to have several adverse effects, with the most common adverse effects related to the gastrointestinal tract $[66,67]$. These effects are caused by stimulating gastrointestinal motility through motilin-like activity [66, 67]. Gastrointestinal symptoms, including anorexia, diarrhoea, abdominal pain and stomach ache, were also reported in COPD patients treated with erythromycin $[13,49,51,52,54]$. The patients with gastrointestinal symptoms did not complete the course of the study [13, 49, 51, 52, 54]. AlBERT et al. [53] also reported hearing decrements in COPD patients treated with azithromycin, which has also been reported in patients with other diseases $[68,69]$. As a result, azithromycin treatment was discontinued in those patients experiencing hearing decrements [53]. Erythromycin and clarithromycin are also associated with ototoxicity such as vertigo, tinnitus, deafness and hearing loss [67]. One COPD patient withdrew from the study by SEEMUNGAL et al. [51] because of tinnitus caused by erythromycin therapy. Macrolide-induced allergic reactions, skin 
eruptions, hepatotoxicity and cardiac arrhythmias, including QTc prolongation on an electrocardiogram [66, 67], were not reported in the COPD patients in the studies cited here [13, 49-54].

\section{BACTERIOLOGY IN LONG-TERM MACROLIDE THERAPY FOR COPD}

SEEMUNGAL et al. [51] demonstrated that pathogens were detected in 17 out of 43 sputum samples from COPD patients and that three samples from the placebo group and two samples from the erythromycin group were resistant to erythromycin at the 12-month follow-up visit. The authors concluded that there were no differences in the bacterial flora of the macrolide and placebo groups. HE et al. [52] showed that there was no difference in the bacterial detection rate of the erythromycin group and the placebo groups, but they did not describe the detection rate for macrolide-resistant bacteria. ALBERT et al. [53] showed that the rate of macrolide resistance in the azithromycin group did not differ from that in the placebo group at the time of enrolment. However, more patients in the placebo group than the azithromycin group became colonised during the course of the study. In contrast, the susceptibility test investigating the pathogens from the COPD patients who were not colonised at the time of enrolment but became colonised during the course of the study revealed that the incidence of resistance to macrolides was higher in the azithromycin group than the placebo group. The authors concluded that COPD patients receiving azithromycin were less likely to become colonised with respiratory pathogens but azithromycin therapy could change microbial resistance patterns [53]. These findings suggest that azithromycin therapy in COPD patients might increase the rate of macrolide resistance. However, neither the bacterial flora nor the pathogen density in the sputum of macrolide-treated patients experiencing either DPB or bronchiectasis changed after treatment with clarithromycin, erythromycin or azithromycin [27, 61, 64]. Likewise, a recent study by SERISIER et al. [65] demonstrated that neither new respiratory pathogens nor erythromycin resistant organisms were detected in the sputum of bronchiectasis patients during 2 months of erythromycin therapy. Although there have not been any reports of patients who were treated with long-term macrolides and experienced a life-threatening infection with macrolide-resistant bacteria, attention must be paid to the induction of macrolide-resistant pathogens [36].

\section{DOSAGE AND EFFECTS OF LONG-TERM MACROLIDE THERAPY IN COPD}

The COPD patients in five out of eight studies cited here [13, 49-52] were treated with 14-member class macrolides, including erythromycin and/or clarithromycin. The macrolide dosage was $200-500 \mathrm{mg} \cdot$ day $^{-1}$ for erythromycin $[49,51,52]$, 200-1,200 mg. day ${ }^{-1}$ for erythromycin [50] or 200-800 mg $\cdot$ day $^{-1}$ for clarithromycin [50]. The macrolide dosage was similar to that used in a report of DPB patients who had been treated with a low-dose of erythromycin $\left(400-600 \mathrm{mg} \cdot\right.$ day $\left.^{-1}\right)$ [34, 35]. Furthermore, BLASI et al. [54] treated COPD patients with azithromycin, a 16-member class macrolide, 3 days per week (500 mg). Gomez et al. [56] treated patients with $500 \mathrm{mg}$ azithromycin daily for 3 days out of every 21 days. In contrast, the COPD patients in the study by ALBERT et al. [53] ingested azithromycin $250 \mathrm{mg}$ daily. This low dose of azithromycin was the same dose that WALTER et al. [38] used for younger CF patients. As reported here, macrolide therapy had clinical effects on COPD patients with frequent exacerbations [49-54], suggesting that macrolide therapy has clinical benefits in a frequent exacerbation COPD phenotype [70]. However, one study showed that macrolide therapy had no effects on COPD patients who do not have frequent exacerbations [13]. These findings suggest that only patients who experience frequent exacerbations may benefit from macrolide therapy. Macrolide therapy also has clinical benefits in COPD patients who have severe disease accompanied by frequent exacerbations, including those patients who receive long-term oxygen or have a tracheostomy or symptoms such as sputum. Adverse effects were reported in a small number of COPD patients who were treated with erythromycin [49, 51, 52], clarithromycin [13] or azithromycin [54], whereas hearing decrements were reported in patients who received ingested azithromycin daily [53]. However, WOLTER et al. [38] reported that none of the younger CF patients experienced hearing loss after treatment with azithromycin. Erythromycin ototoxicity (such as hearing loss and deafness) has also been reported previously [67]. Thus, the prevalence of ototoxicity due to long-term macrolide therapy may differ between erythromycin, clarithromycin and azithromycin, or between younger and older patients.

\section{COPD EXACERBATION MECHANISMS}

Bacteria such as H. influenzae, M. catarrhalis and S. pneumonia have been detected in $50-60 \%$ of the COPD patients who experience exacerbations [41-43]. These bacteria can enhance mucus secretion, inhibit the ciliary beat frequency, and cause airway epithelial injury, thereby impairing mucociliary clearance (fig. 1) [71, 72]. Infection with these bacteria also stimulates the cells in the airways and the lung parenchyma to induce pro-inflammatory substrates, interleukin (IL)-8 and leukotriene $\mathrm{B}_{4}$ (fig. 1) [15, 30 47, 73, 74]. These substrates induce inflammation by causing neutrophils to infiltrate the airways and alveoli, and by activating neutrophils to release cytotoxic products and neutrophil elastase [47, 75]. Neutrophil elastase causes airway smooth muscle contraction, mucosal oedema and mucin secretion, thereby resulting in the limitation of airflow and gas exchange in the airways and the alveoli, respectively (fig. 1) [47, 76-80].

Various species of viruses, such as rhinovirus (RV), influenza virus and respiratory syncytial virus (RSV) have also been detected in the induced sputum and nasal samples or the blood of $23-56 \%$ of patients experiencing COPD exacerbations [44-46]. The production and secretion of a variety of mediators, including IL-6, IL-8 and interferon gamma-induced protein-10, are stimulated by RV, influenza virus and RSV in airway epithelial cells and the blood [81-87]. Viral infection-induced mediator release may also stimulate neutrophils and induce airway inflammation and mucin secretion through similar mechanisms that are induced by bacterial infection $[47,88]$. In fact, RV infection induces the infiltration of neutrophils, lymphocytes and eosinophils into the nasal and bronchial mucosa [89, 90]. Furthermore, RV infection can stimulate mucin secretion from airway surface epithelial cells and submucosal gland cells [91] and airway smooth muscle contraction through IL-1 and IL-5 (fig. 1) [92]. In contrast to the weak cytotoxic effects caused by RV, the influenza virus causes 
a) Mechanisms of COPD exacerbation

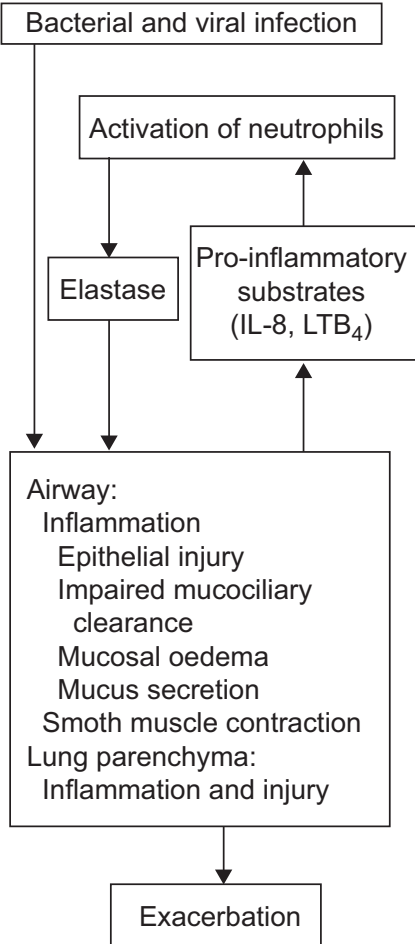

b) Mechanisms for the macrolide-mediated prevention of COPD exacerbation

Inhibition of neutrophil chemotaxis and survival

\begin{tabular}{|l|}
\hline $\begin{array}{l}\text { Modulation of } \\
\text { pro-inflammatory cytokine } \\
\text { secretion }\end{array}$ \\
\hline
\end{tabular}

\section{Anti-bacterial effects} Inhibition of:

Virulence factor production Cytokine production Pseudomonas adhesion Biofilm formation Quorum sensing mechanisms

Anti-viral effects

Modulation of mucus secretion

FIGURE 1. a) Bacterial and viral infection-induced chronic obstructive (COPD) exacerbation mechanisms and b) macrolide contributions to the prevention of COPD exacerbations and the relationships between them. IL-8: interleukin-8, LTB leukotriene $\mathrm{B}_{4}$.

epithelial cell damage in the airways and lung parenchyma [93] and may affect the barrier function of the endothelium [94]. These mechanisms induce fluid accumulation and epithelial detachment, as well as subsequent airflow limitation and exudative alveolar destruction [93]. Secondary bacterial infections in the respiratory tract and lung parenchyma that are followed by influenza virus and RV infection may also be associated with COPD exacerbations $[95,96]$. These mechanisms may cause airway inflammation and subsequent COPD

exacerbations following bacterial and viral infections (fig. 1) $[35,47,48,88,97]$.

\section{MACROLIDE CHARACTERISTICS}

Macrolides are macrocyclic lactones consisting of at least 8membered rings. This very large class $(>2,000$ compounds) comprises both natural substances isolated from fungi and other organisms and synthetic molecules with similar structures [67]. The most common agents used in the clinic are semi-synthetic 14-, 15- or 16-membered ring antibiotics related to erythromycin. These agents include erythromycin, clarithromycin and roxithromycin as members of the 14-member class and azithromycin as the prototypical 15-member compound [98]. Macrolide antibiotics bind to the $50 S$ ribosomes of both prokaryotes and eukaryotes, inhibiting the transpeptidation or translocation of nascent peptides. Macrolides accumulate in many tissues, such as the fluid of the epithelial lining, and easily enter host defence cells such as macrophages and polymorphonuclear leukocytes. The macrolide concentrations in respiratory tract tissues and extracellular fluids are higher than those in the serum (especially after the ingestion of clarithromycin), making them useful for airway and alveolar infections [67].

\section{MECHANISMS FOR THE MACROLIDE-MEDIATED PREVENTION OF COPD EXACERBATIONS Anti-inflammatory effects of macrolides}

KADOTA et al. [14] demonstrated that the high percentage of neutrophils in the bronchoalveolar lavage fluid from patients with DPB decreased after erythromycin treatment. The previously elevated neutrophil chemotactic activities were also reduced after erythromycin treatment (table 2) [14, 15].

TAKIZAWA et al. [16] and DESAKI et al. [18] demonstrated that macrolides have effects on bronchial epithelial cells, including suppressing mRNA levels and the release of IL-8 through the activation of nuclear factor- $\kappa \mathrm{B}$ and activator protein-1 [18]. The anti-inflammatory effects of macrolide antibiotics were also demonstrated in human peripheral blood monocytes and polymorphonuclear neutrophils [15, 100, 102].

Several other macrolide-mediated anti-inflammatory effects have also been reported in the sputum of patients with COPD, including decreases in the total cell counts, neutrophil chemotaxis, and the levels of IL- 8 and tumour necrosis factor (TNF)- $\alpha$ $[13,19]$.

\section{TABLE 2 Anti-inflammatory and physiological effects of macrolides}

Effects $\quad$ First author [ref.]

Modulation of pro-inflammatory cytokine secretion

Modulation of mucus secretion Inhibition of neutrophil chemotaxis Inhibition of neutrophil survival Stimulation of defensin secretion Anti-bacterial effects

Anti-viral effects
OISHI [99], KhaIR [15], TaKizAwa [16], Suzaki [17], Khan [100], DeSAKI [18], SuzUKI [22], KIKUchI [101], BANERJEe [13], BASYIGIT [19], REATO [102]

TAmaoki [27], Rubin [103], Tagaya [62], Shimizu [28], InOUe [91], Araki [30]

Kadota [14], Oda [104], KhaIR [15], VILlagrasa [105]

YAMASAWA [106]

ISHIZAWA [31]

KhalR [15], Tateda [32], Comte [107], TAKaKı [108], Wozniak [33], Anderson [109], IShida [110], Araki [30], HALLDORSSON [111]

Sato [20], Tsurita [21], Suzuki [22], Miyamoto [24], Kido [23], Asada [25], Gielen [112], Yamaya [26] 


\section{Inhibitory effects on mucus secretion}

TAMAOKI et al. [27] conducted a parallel, double-blind, placebocontrolled study to determine the effects that long-term clarithromycin administration has on the amount of sputum in patients with clinical conditions that are associated with excessive airway secretions. A total of 31 patients were divided into two groups: a clarithromycin group (100 mg twice a day) and a placebo group, in which 16 patients had chronic bronchitis and seven patients had bronchiectasis. The authors reported that treatment with clarithromycin decreased sputum production [27]. TAGAYA et al. [62] also demonstrated that treatment with clarithromycin decreased the sputum volume in 16 patients with chronic bronchitis $(n=5)$ or bronchiectasis $(n=11)$.

SHIMIZU et al. [28] examined the effects that macrolide antibiotics have on mucus hypersecretion in vivo, reporting that clarithromycin inhibited ovalbumin (OVA)- and lipopolysaccharide (LPS)-induced mucus production induced by the intranasal instillation of OVA in OVA-sensitised rats and intranasal LPS instillation.

In vitro studies have demonstrated that macrolide antibiotics such as erythromycin [28, 29], clarithromycin [28] and azithromycin [30] have inhibitory effects on mucin or MUC5AC production or secretion after stimulation with TNF- $\alpha$ [28], RV infection [29] or extract of $H$. influenzae [30] in airway epithelial cells.

\section{Inhibitory effects on bacterial virulence and biofilms}

ANDERSON et al. [109] demonstrated that clarithromycin reduces the production of pneumolysin, a key virulence factor in the infection of $S$. pneumoniae. Macrolides reduce the production of pro-inflammatory cytokines, soluble intercellular adhesion molecule (ICAM)-1 and mucin in cells such as airway epithelial cells in response to endotoxin and extract of $H$. influenzae [15, 30, 108, 110]. Azithromycin also maintains the integrity of airway epithelial cells during P. aeruginosa infection [111]. These findings suggest that macrolides may inhibit virulence factor production and the inflammation caused by the bacteria that induce COPD exacerbations. Furthermore, clarithromycin inhibits the twitching motility of $P$. aeruginosa [33], and azithromycin inhibits the quorum-sensing circuitry of $P$. aeruginosa, which relates to virulence factor production $[32,107]$. In addition, incubating $P$. aeruginosa with clarithromycin altered the structure and architecture of the biofilm [33]. These findings suggest that macrolides may modulate the virulence of bacteria at the early and late stages of COPD (table 2).

\section{Inhibitory effects on virus infection}

SATO et al. [20] and TsURITA et al. [21] reported that erythromycin and clarithromycin increased the survival rate of mice infected with a lethal dose of influenza virus. They also suggested that the reduction in lung injury and the severity of pneumonia were associated with the reduced production of nitric oxide, reactive oxygen species and interferon (IFN)- $\gamma$ [20] and the elevated IL-12 levels [21] induced by erythromycin and clarithromycin. KIDO et al. [23] and MiYамото et al. [24] also demonstrated that clarithromycin suppresses the growth of the influenza virus and its release in mouse airways and epithelial cells, respectively. Furthermore, YAMAYA et al. [26] reported that clarithromycin decreased the release of viruses and cytokines into supernatant fluids in human tracheal epithelial cells that were infected with seasonal type A influenza (H3N2) by reducing the expression of the viral receptor and inhibiting viral RNA entry.

SuZUKI et al. [22] showed that erythromycin inhibited RV infection by reducing the levels of ICAM-1, an RV receptor, and/or by blocking RV RNA entry and that erythromycin reduces the production of pro-inflammatory cytokines in the human tracheal epithelial cells. GIELEN et al. [112] showed that IFNs were induced in human bronchial epithelial cells when the cells were pretreated with azithromycin and infected with RV and that this effect may relate to the shorter duration of exacerbations in COPD patients who are treated with macrolides. ASADA et al. [25] have also reported that macrolides have inhibitory effects on RSV virus infection in human airway epithelial cells.

These anti-viral and anti-inflammatory effects of macrolides may be associated with the inhibition of viral infectioninduced COPD exacerbations, although there is no evidence that macrolides reduce the frequency of viral infection in COPD exacerbations.

\section{Summary of the possible mechanisms by which macrolides exert clinical benefits on COPD exacerbations}

As described above and in other reports, macrolides have been found to have various functions other than antimicrobial effects, including anti-inflammatory effects [13-19], reduced mucus secretion [27-30], inhibitory effects on bacterial virulence and biofilm formation [15, 30, 32, 33, 107, 108, 110, 111], enhanced production of antimicrobial peptides and human $\beta$ defensins [31], and anti-viral effects [20-26, 112]. The physiological functions of macrolides, including those reported by other authors [17, 99, 101-106], are shown in figure 1 and table 2. Previous studies have suggested that the clinical effects that erythromycin has on DPB are associated with immunomodulatory and physiological activities other than antimicrobial effects [36]. Based on these findings, the clinical benefits that macrolides have on the prevention of COPD exacerbations are also considered to be mediated by these immunomodulatory and other physiological activities [49].

\section{CONCLUSIONS}

The recent reports studying the beneficial effects that macrolides have on the attenuation of acute COPD exacerbations are summarised in this review. Interactions between the host immune system and bacterial and viral infections are associated with COPD exacerbations, and macrolides might attenuate the overall risk of mortality. The contribution that macrolides make to COPD exacerbations may carry a benefit for human survival, despite the worry of an increase in the number of macrolideresistant bacterial strains.

\section{STATEMENT OF INTEREST}

Statements of interest for all authors can be found at www.erj. ersjournals.com/site/misc/statements.xhtml

\section{REFERENCES}

1 Vincken W, van Noord JA, Greehorst AP, et al. Improved health outcomes in patients with COPD during 1 yr's treatment with tiotropium. Eur Respir J 2002; 19: 209-216.

2 Tashkin DP, Celli B, Senn S, et al. A 4-year trial of tiotropium in chronic obstructive pulmonary disease. N Engl J Med 2008; 359: 1543-1554. 
3 Mahler DA, Donohue JF, Barbee RA, et al. Efficacy of salmeterol xinafoate in the treatment of COPD. Chest 1999; 115: 957-965.

4 Jones PW, Willits LR, Burge PS, et al. Disease severity and the effect of fluticasone propionate on chronic obstructive pulmonary disease exacerbations. Eur Respir J 2003; 21: 68-73.

5 Maltais F, Ostinelli J, Bourbeau J, et al. Comparison of nebulized budesonide and oral prednisolone with placebo in the treatment of acute exacerbations of chronic obstructive pulmonary disease: a randomized controlled trial. Am J Respir Crit Care Med 2002; 165: 698-703.

6 Calverley PM, Boonsawat W, Cseke Z, et al. Maintenance therapy with budesonide and formoterol in chronic obstructive pulmonary disease. Eur Respir J 2003; 22: 912-919.

7 Calverley PM, Anderson JA, Celli B, et al. Salmeterol and fluticasone propionate and survival in chronic obstructive pulmonary disease. $N$ Engl J Med 2007; 356: 775-789.

8 Aaron SD, Vandemheen KL, Fergusson D, et al. Tiotropium in combination with placebo, salmeterol, or fluticasone-salmeterol for treatment of chronic obstructive pulmonary disease: a randomized trial. Ann Intern Med 2007; 146: 545-555.

9 Welte T, Miravitlles M, Hernandez P, et al. Efficacy and tolerability of budesonide/formoterol added to tiotropium in patients with chronic obstructive pulmonary disease. Am J Respir Crit Care Med 2009; 180: 741-750.

10 Poole PJ, Black PN. Oral mucolytic drugs for exacerbation of chronic obstructive pulmonary disease: systematic review. BMJ 2001; 322: 1271-1274.

11 Yasuda H, Yamaya M, Sasaki T, et al. Carbocisteine reduces frequency of common colds and exacerbations in patients with chronic obstructive pulmonary disease. J Am Geristr Soc 2006; 54: 378-380.

12 Zheng JP, Kang J, Huang SG, et al. Effect of carbocisteine on acute exacerbation of chronic obstructive pulmonary disease (PEACE Study): a randomised placebo-controlled study. Lancet 2008; 371: 2013-2018.

13 Banerjee D, Honeybourne D, Khair OA. The effect of oral clarithromycin on bronchial airway inflammation in moderateto-severe stable COPD: a randomized controlled trial. Treat Respir Med 2004; 3: 59-65.

14 Kadota J, Sakito O, Kohno S, et al. A mechanism of erythromycin treatment in patients with diffuse panbronchiolitis. Am Rev Respir Dis 1993; 147: 153-159.

15 Khair OA, Devalia JL, Abdelaziz MM, et al. Effect of erythromycin on Haemophilus influenzae endotoxin-induced release of IL-6, IL-8 and sICAM-1 by cultured human bronchial epithelial cells. Eur Respir J 1995; 8: 1451-1457.

16 Takizawa H, Desaki M, Ohtoshi T, et al. Erythromycin modulates IL-8 expression in human bronchial epithelial cells: studies with normal and inflamed airway epithelium. Am J Respir Crit Care Med 1997; 156: 266-271.

17 Suzaki H, Asano K, Ohki S, et al. Suppressive activity of a macrolide antibiotic, roxithromycin, on pro-inflammatory cytokine production in vitro and in vivo. Mediators Inflamm 1999; 8: 199-204.

18 Desaki M, Takizawa $H$, Ohtoshi $T$, et al. Erythromycin suppresses nuclear factor- $\mathrm{\kappa} \mathrm{B}$ and activator protein-1 activation in human bronchial epithelial cells. Biochem Biophys Res Commun 2000; 267: 124-128.

19 Basyigit I, Yildiz F, Ozkara SK, et al. The effect of clarithromycin on inflammatory markers in chronic obstructive pulmonary disease: preliminary data. Ann Pharmacother 2004; 38: 783-792.

20 Sato K, Suga M, Akaike $\mathrm{T}$, et al. Therapeutic effect of erythromycin on influenza virus-induced lung injury in mice. Am J Respir Crit Care Med 1998; 157: 853-857.

21 Tsurita M, Kurokawa M, Imakita M, et al. Early augmentation of interleukin (IL)-12 level in the airway of mice administered orally with clarithromycin or intranasally with $1 \mathrm{~L}-12$ results in alleviation of influenza infection. J Pharmacol Exp Ther 2001; 298 362-368

22 Suzuki T, Yamaya M, Sekizawa K, et al. Erythromycin inhibits rhinovirus infection in cultured human tracheal epithelial cells. Am J Respir Crit Care Med 2002; 165: 1113-1118.

23 Kido H, Okumura Y, Yamada H, et al. Secretory leukoprotease inhibitor and pulmonary surfactant serve as principal defenses against influenza A virus infection in the airway and chemical agents up-regulating their levels may have therapeutic potential. Biol Chem 2004; 385: 1029-1034.

24 Miyamoto D, Hasegawa S, Sriwilaijaroen N, et al. Clarithromycin inhibits progeny virus production from human influenza virusinfected host cells. Biol Pharma Bull 2008; 31: 217-222.

25 Asada M, Yoshida M, Suzuki T, et al. Macrolide antibiotics inhibit respiratory syncytial virus infection in human airway epithelial cells. Antiviral Res 2009; 83: 191-200.

26 Yamaya M, Shinya K, Hatachi Y, et al. Clarithromycin inhibits type a seasonal influenza virus infection in human airway epithelial cells. J Pharmacol Exp Ther 2010; 333: 81-90.

27 Tamaoki J, Takeyama K, Tagaya E, et al. Effect of clarithromycin on sputum production and its rheological properties in chronic respiratory tract infections. Antimicrob Agents Chemother 1995; 39: 1688-1690.

28 Shimizu T, Shimizu S, Hattori R, et al. In vivo and in vitro effects of macrolide antibiotics on mucus secretion in airway epithelial cells. Am J Respir Crit Care Med 2003; 168: 581-587.

29 Inoue $\mathrm{D}$, Kubo $\mathrm{H}$, Sasaki $\mathrm{T}$, et al. Erythromycin attenuates MUC5AC synthesis and secretion in cultured human tracheal cells infected with RV14. Respirology 2008; 13: 215-220.

30 Araki N, Yanagihara K, Morinaga Y, et al. Azithromycin inhibits nontypeable Haemophilus influenzae-induced MUC5AC expression and secretion via inhibition of activator protein-1 in human airway epithelial cells. Eur J Pharmacol 2010; 644: 209-214.

31 Ishizawa K, Suzuki T, Yamaya M, et al. Erythromycin increases bactericidal activity of surface liquid in human airways epithelial cells. Am J Physiol 2005; 289: L565-L573.

32 Tateda K, Comte R, Pechere JC, et al. Azithromycin inhibits quorum sensing in Pseudomonas aeruginosa. Antimicrob Agents Chemother 2001; 45: 1930-1933.

33 Wozniak DJ, Keyser R. Effects of subinhibitory concentrations of macrolide antibiotics on Pseudomonas aeruginosa. Chest 2004; 125: Suppl. 2, 62S-69S.

34 Kudoh S, Kimura K, Uetake K, et al. Clinical effects of low-dose macrolide antibiotic on diffuse panbronchiolitis. Abstract of annual meeting. Jpn J Thorac Dis 1984; 22: 254.

35 Kudoh S, Azuma A, Yamamoto M, et al. Improvement of survival in patients with diffuse panbronchiolitis. Am J Respir Crit Care Med 1998; 157: 1829-1832.

36 Azuma A, Kudoh S. Diffuse panbronchiolitis in East Asia. Respirology 2006; 11: 249-261.

37 Jaffe A, Francis J, Rosenthal M, et al. Long-term azithromycin may improve lung function in children with cystic fibrosis. Lancet 1998; 351: 420.

38 Wolter J, Seeney S, Bell S, et al. Effect of long term treatment with azithromycin on disease parameters in cystic fibrosis: a randomised trial. Thorax 2002; 57: 212-216.

39 Crosbie PA, Woodhead MA. Long-term macrolide therapy in chronic inflammatory airway diseases. Eur Respir J 2009; 33 171-181.

40 Friedlander AL, Albert RK. Chronic macrolide therapy in inflammatory airway diseases. Chest 2011; 138: 1202-1212.

41 Fagon JY, Chastre J, Trouillet JL, et al. Characterization of distal bronchial microflora during acute exacerbation of chronic bronchitis. Use of the protected specimen brush technique in 54 mechanically ventilated patients. Am Rev Respir Dis 1990; 142: 1004-1008. 
42 Monso E, Ruiz J, Rosell A, et al. Bacterial infection in chronic obstructive pulmonary disease. A study of stable and exacerbated outpatients using the protected specimen brush. Am J Respir Crit Care Med 1995; 152: 1316-1320.

43 Soler N, Torres A, Ewig S, et al. Bronchial microbial patterns in severe exacerbations of chronic obstructive pulmonary disease (COPD) requiring mechanical ventilation. Am J Respir Crit Care Med 1998; 157: 1498-1505.

44 Seemungal TA, Harper-Owen R, Bhowmik A, et al. Detection of rhinovirus in induced sputum at exacerbation of chronic obstructive pulmonary disease. Eur Respir J 2000; 16: 677-683.

45 Seemungal T, Harper-Owen R, Bhowmik A, et al. Respiratory viruses, symptoms, and inflammatory markers in acute exacerbations and stable chronic obstructive pulmonary disease. Am J Respir Crit Care Med 2001; 164: 1618-1623.

46 Rohde G, Wiethege A, Borg I, et al. Respiratory viruses in exacerbations of chronic obstructive pulmonary disease requiring hospitalisation: a case-control study. Thorax 2003; 58: 37-42.

47 Sethi S. New developments in the pathogenesis of acute exacerbations of chronic obstructive pulmonary disease. Curr Opin Infect Dis 2004; 17: 113-119.

48 Sethi S, Malla P, Johnston SL. New paradigms in the pathogenesis of chronic obstructive pulmonary disease II. Proc Am Thorac Soc 2009; 6: 532-534.

49 Suzuki T, Yanai M, Yamaya M, et al. Erythromycin and common cold in COPD. Chest 2001; 120: 730-733.

50 Yamaya M, Azuma A, Tanaka H, et al. Inhibitory effects of macrolide antibiotics on exacerbations and hospitalization in chronic obstructive pulmonary disease in Japan: a retrospective multicenter analysis. J Am Geriatr Soc 2008; 56: 1358-1360.

51 Seemungal TA, Wilkinson TM, Hurst JR, et al. Long-term erythromycin therapy is associated with decreased chronic obstructive pulmonary disease exacerbations. Am J Respir Crit Care Med 2008; 178: 1139-1147.

52 He ZY, Ou L, Zhang JQ, et al. Effect of 6 months of erythromycin treatment on inflammatory cells in induced sputum and exacerbations in chronic obstructive pulmonary disease. Respiration 2010; 80: 445-452.

53 Albert RK, Connett J, Bailey WC, et al. Azithromycin for prevention of exacerbations of COPD. N Engl J Med 2011; 365: 689-698.

54 Blasi F, Bonardi D, Aliberti S, et al. Long-term azithromycin use in patients with chronic obstructive pulmonary disease and tracheostomy. Pulm Pharmacol Ther 2010; 23: 200-207.

55 Friedlander AL, Albert RK. Chronic macrolide therapy in inflammatory airways diseases. Chest 2010; 138: 1202-1212.

56 Gomez J, Banos V, Simarro E, et al. Prospective, comparative study (1994-1998) of the influence of short-term prophylactic treatment with azithromycin on patients with advanced COPD. Rev Esp Quimioterap 2000; 13: 379-383.

57 O'Donnell AE. Bronchiectasis in patients with COPD: a distinct COPD phenotype? Chest 2011; 140: 1107-1108.

58 Martínez-García MA, Soler-Cataluña JJ, Sanz YD, et al. Factors associated with bronchiectasis in patients with COPD. Chest 2011; 140: 1130-1137.

59 Koh YY, Lee MH, Sun YH, et al. Effect of roxithromycin on airway responsiveness in children with bronchiectasis: a doubleblind, placebo-controlled study. Eur Respir J 1997; 10: 994-999.

60 Nakamura H, Fujishima S, Inoue T, et al. Clinical and immunoregulatory effects of roxithromycin therapy for chronic respiratory tract infection. Eur Respir J 1999; 13: 1371-1379.

61 Tsang KWT, Ho PI, Chan KN, et al. A pilot study of low-dose erythromycin in bronchiectasis. Eur Respir J 1999; 13: 361-364.

62 Tagaya E, Tamaoki J, Kondo M, et al. Effect of a short course of clarithromycin therapy on sputum production in patients with chronic airway hypersecretion. Chest 2002; 122: 213-218.
63 Cymbala AA, Edmonds LC, Bauer MA, et al. The diseasemodifying effects of twice-weekly oral azithromycin in patients with bronchiectasis. Treat Respir Med 2005; 4: 117-122.

64 Davies G, Wilson R. Prophylactic antibiotic treatment of bronchiectasis with azithromycin. Thorax 2004; 59: 540-541.

65 Serisier DJ, Martin ML. Long-term, low-dose erythromycin in bronchiectasis subjects with frequent infective exacerbations. Respir Med 2011; 105: 946-949.

66 McConnell SA, Amsden GW. Review and comparison of advanced-generation macrolides clarithromycin and dirithromycin. Pharmacotherapy 1999; 19: 404-415.

67 Jain R, Danziger LH. The macrolide antibiotics: a pharmacokinetic and pharmacodynamic overview. Curr Pharm Des 2004; 10: 3045-3053.

68 Tseng AL, Dolovich L, Salit E. Azithromycin-related ototoxicity in patients infected with human immunodeficiency virus. Clin Infect Dis 1997; 24: 76-77.

69 Lo SH, Kotabe S, Mitsunaga L. Azithromycin-induced hearing loss. Am J Health Syst Pharm 1999; 56: 380-383.

70 Hurst JR, Vestbo J, Anzueto A, et al. Evaluation of COPD Longitudinally to Identify Predictive Surrogate Endpoints (ECLIPSE) Investigators. Susceptibility to exacerbation in chronic obstructive pulmonary disease. N Engl J Med 2010; 363: 1128-1138.

71 Wilson R, Roberts D, Cole P. Effect of bacterial products on human ciliary function in vitro. Thorax 1984; 40: 125-131.

72 Read RC, Wilson R, Rutman A, et al. Interaction of nontypeable Haemophilus influenzae with human respiratory mucosa in vitro. J Infect Dis 1991; 163: 549-558.

73 Gompertz S, O'Brien C, Bayley DL, et al. Changes in bronchial inflammation during acute exacerbations of chronic bronchitis. Eur Respir J 2001; 17: 1112-1119.

74 Berenson CS, Wrona CT, Grove LJ, et al. Impaired alveolar macrophage response to Haemophilus antigens in chronic obstructive lung disease. Am J Respir Crit Care Med 2006; 174: $31-40$.

75 Sethi S, Muscarella K, Evans N, et al. Airway inflammation and etiology of acute exacerbations of chronic bronchitis. Chest 2000; 118: $1557-1565$

76 Takayama N, Uchida K. Epithelium-dependent and -independent inhibitory effects of sivelestat, a neutrophil elastase inhibitor, on substance P-induced contraction of airway smooth muscle in lipopolysaccharide-treated guinea-pigs. J Smooth Muscle Res 2005; 41: 257-270.

77 Waller DA, Keavey P, Woodfine L, et al. Pulmonary endothelial permeability changes after major lung resection. Ann Thorac Surg 1996; 61: 1435-1440.

78 Kubo K, Kobayashi T, Hayano T, et al. Effects of ONO-5046., a specific neutrophil elastase inhibitor, on endotoxin-induced lung injury in sheep. J Appl Physiol 1994; 77: 1333-1340.

79 Schraufstatter I, Revak SD, Cochrane CG. Biochemical factors in pulmonary inflammatory disease. Fed Proc 1984; 43: 2807-2810.

80 Fischer BM, Voynow JA. Neutrophil elastase induces MUC5AC gene expression in airway epithelium via a pathway involving reactive oxygen species. Am J Respir Cell Mol Biol 2002; 26: $447-452$.

81 Noah TL, Becker S. Respiratory syncytial virus-induced cytokine production by a human bronchial epithelial cell line. Am J Physiol 1993; 265: L472-L478.

82 Subauste MC, Jacoby DB, Richards SM, et al. Infection of a human respiratory epithelial cell line with rhinovirus. Induction of cytokine release and modulation of susceptibility to infection by cytokine exposure. J Clin Invest 1995; 96: 549-557.

83 Terajima M, Yamaya M, Sekizawa K, et al. Rhinovirus infection of primary cultures of human tracheal epithelium: role of ICAM-1 and IL-1ß. Am J Physiol 1997; 273: L749-L759.

84 Van Lenten BJ, Wagner AC, Navab $\mathrm{M}$, et al. D-4F, an apolipoprotein A-I mimetic peptide, inhibits the inflammatory 
response induced by influenza A infection of human type II pneumocytes. Circulation 2004; 110: 3252-3258.

85 Tripp RA, Oshansky C, Alvarez R. Cytokines and respiratory syncytial virus infection. Proc Am Thorac Soc 2005; 2: 147-149.

86 de Jong MD, Simmons CP, Thanh TT, et al. Fatal outcome of human influenza $\mathrm{A}\left(\mathrm{H}_{5} \mathrm{~N}_{1}\right)$ is associated with high viral load and hypercytokinemia. Nat Med 2006; 12: 1203-1207.

87 Deng R, Lu M, Korteweg C, et al. Distinctly different expression of cytokines and chemokines in the lungs of two $\mathrm{H}_{5} \mathrm{~N}_{1}$ avian influenza patients. J Pathol 2008; 216: 328-336.

88 Papi A, Bellettato CM, Braccioni F, et al. Infections and airway inflammation in chronic obstructive pulmonary disease severe exacerbations. Am J Respir Crit Care Med 2006; 173: 1114-1121.

89 Levandowski RA, Weaver CW, Jackson GG. Nasal-secretion leukocyte populations determined by flow cytometry during acute rhinovirus infection. J Med Virol 1988; 25: 423-432.

90 Fraenkel DJ, Bardin PG, Sanderson G, et al. Lower airways inflammation during rhinovirus colds in normal and in asthmatic subjects. Am J Respir Crit Care Med 1995; 151: 879-886.

91 Inoue $\mathrm{D}$, Yamaya $\mathrm{M}$, Sasaki $\mathrm{T}$, et al. Mechanisms of mucin production by rhinovirus infection in cultured human tracheal surface epithelium and submucosal glands. Respir Physiol Neurobiol 2006; 154: 484-499.

92 Grunstein MM, Hakonarson $\mathrm{H}$, Maskeri N, et al. Autocrine cytokine signaling mediates effects of rhinovirus on airway responsiveness. Am J Physiol 2000; 278: L1146-L1153.

93 Mauad T, Hajjar LA, Callegari GD, et al. Lung pathology in fatal novel human influenza A (H1N1) infection. Am J Respir Crit Care Med 2010; 181: 72-79.

94 Wang S, Lea TQ, Kurihara N, et al. Influenza virus-cytokineprotease cycle in the pathogenesis of vascular hyperpermeability in severe influenza. J Infect Dis 2010; 202: 991-1001.

95 Brundage F. Interactions between influenza and bacterial respiratory pathogens: implications for pandemic preparedness. Lancet Infect Dis 2006; 6: 303-312.

96 Smith CB, Golden C, Klauber MR, et al. Interactions between viruses and bacteria in patients with chronic bronchitis. J Infect Dis 1976; 134: 552-561.

97 Johnston SL. Overview of virus-induced airway disease. Proc Am Thorac Soc 2005; 2: 150-156.

98 Labro MT. Cellular and molecular effects of macrolides on leukocyte function. Curr Pharm Des 2004; 10: 3067-3080.

99 Oishi K, Sonoda F, Kobayashi S, et al. Role of interleukin-8 (IL-8) and an inhibitory effect of erythromycin on IL-8 release in the airways of patients with chronic airway diseases. Infect Immun 1994; 62: 4145-4152.
100 Khan AA, Slifer TR, Araujo FG, et al. Effect of clarithromycin and azithromycin on production of cytokines by human monocytes. Int J Antimicrob Agent 1999; 11: 121-132.

101 Kikuchi T, Hagiwara K, Honda Y, et al. Clarithromycin suppresses lipopolysaccharide-induced interleukin-8 production by human monocytes through AP-1 and NF- $\mathrm{kB}$ transcription factors. J Antimicrob Chemother 2002; 49: 745-755.

102 Reato G, Cuffini AM, Tullio V, et al. Immunomodulating effect of antimicrobial agents on cytokine production by human polymorphonuclear neutrophils. Int J Antimicrob Agent 2004; 23: 150-154.

103 Rubin BK, Druce H, Ramirez OE, et al. Effect of clarithromycin on nasal mucus properties in healthy subjects and in patients with purulent rhinitis. Am J Respir Crit Care Med 1997; 155: 2018-2023.

104 Oda H, Kadota J, Kohno S, et al. Erythromycin inhibits neutrophil chemotaxis in bronchoalveoli of diffuse panbronchiolitis. Chest 1994; 106: 1116-1123.

105 Villagrasa V, Berto L, Cortijo J, et al. Effects of erythromycin on chemoattractant-activated human polymorphonuclear leukocytes. Gen Pharmac 1997; 29: 605-609.

106 Yamasawa H, Oshikawa K, Ohno S, et al. Macrolides inhibit epithelial cell-mediated neutrophil survival by modulating granulocyte macrophage colony-stimulating factor release. Am J Respir Cell Mol Biol 2004; 30: 569-575.

107 Comte R, Pechere JC, Kohler T, et al. Azithromycin inhibits quorum sensing in Pseudomonas aeruginosa. Antimicrob Agents Chemother 2001; 45: 1930-1933.

108 Takaki M, Ushikai M, Deguchi K, et al. The role of nuclear factorkappa B in interleukin-8 expression by human adenoidal fibroblasts. Laryngoscope 2003; 113: 1378-1385.

109 Anderson R, Steel HC, Cockeran R, et al. Clarithromycin alone and in combination with ceftriaxone inhibits the production of pneumolysin by both macrolide-susceptible and macrolideresistant strains of Streptococcus pneumoniae. J Antimicrob Chemother 2007; 59: 224-229.

110 Ishida $Y$, Abe $Y$, Harabuchi $Y$. Effects of macrolides on antigen presentation and cytokine production by dendritic cells and $\mathrm{T}$ lymphocytes. Int J Pediatr Otorhi 2007; 71: 297-305.

111 Halldorsson S, Gudjonsson T, Gottfredsson M, et al. Azithromycin maintains airway epithelial integrity during Pseudomonas aeruginosa infection. Am J Respir Cell Mol Biol 2010; 42: 62-68.

112 Gielen V, Johnston SL, Edwards MR. Azithromycin induces antiviral responses in bronchial epithelial cells. Eur Respir J 2010; 36 : 646-654. 